\title{
The Formation of Specific Synaptic Connections Between Muscle Sensory and Motor Neurons in the Absence of Coordinated Patterns of Muscle Activity
}

\author{
Eric Frank \\ Department of Neurobiology, Anatomy and Cell Science, University of Pittsburgh School of Medicine, Pittsburgh, \\ Pennsylvania 15261
}

The influence of patterned neuronal activity on the formation of specific monosynaptic connectlons between muscle sensory and motor neurons was studied in the developing spinal cord of the bullfrog. Motor innervation of the forelimb was disrupted in tadpoles by resection of the brachial ventral root before these synaptic connections began to form in the spinal cord. In those frogs accepted for analysis, motor reinnervation of the forelimb was nonspecific and there was no coordinated movement of the limb. Synaptic connections therefore developed in the absence of temporal correlations of activity in muscle spindle afferents and motoneurons. Despite this disruption, afferent fibers supplying the triceps brachii muscles selectively innervated a restricted subpopulation of brachial motoneurons. Those motoneurons that received large synaptic inputs from afferents in one branch of the triceps nerve also received large inputs from afferents in the other triceps branches. Inputs from afferents supplying other muscles were not correlated with those from triceps afferents, suggesting the existence of a property common to all triceps afferents causing them to innervate a common subpopulation of motoneurons. These results show that in the absence of normal patterned sensory activity, sufficient cues still exist to permit the formation of specific sets of synaptic connections, and they argue indirectly for the existence of chemical labels that can determine the pattern of these connections.

During the development of the nervous system, a variety of mechanisms probably act in concert to ensure the formation of the correct patterns of synaptic connections. Neuroblasts must be instructed to differentiate into particular types of neurons and grow toward their targets at times when the extracellular environment is conducive to such growth. The axons of these neurons must be able to recognize specific pathways, both inside and outside the nervous system, that guide them to appropriate target areas. And finally, within these areas, the correct subpopulations of pre- and postsynaptic cells must establish synaptic contact with each other, either from the outset or through a rearrangement of an initial, less precise set of connections.

Received Dec. 26, 1989; revised Feb. 14, 1989; accepted Feb. 26, 1990.

It is a pleasure to acknowledge valuable discussions with Drs. B. Mendelson, J. Sanes, and C. Smith and the excellent technical assistance of L. Corwin and $K$ Ellison. This work was supported by a grant from the National Science Foundation.

Correspondence should be addressed to Eric Frank, Department of Neurobiology, Anatomy and Cell Science, University of Pittsburgh School of Medicine, 3550 Terrace Street, Pittsburgh, PA 15261.

Copyright (C) 1990 Society for Neuroscience $0270-6474 / 90 / 072250-11 \$ 03.00 / 0$
A convenient experimental system for studying, in the vertebrate CNS, this third aspect of neural development, i.e., the actual formation of specific synaptic connections, is the set of monosynaptic excitatory connections between muscle spindle afferent fibers and motoneurons projecting to limb muscles. These are the connections that underlie the simple myotatic stretch reflex. Intracellular recordings can be made from functionally identified motoneurons and the synaptic input to these neurons from specific groups of spindle afferent fibers can be elicited by stimulation of individual muscle nerves. These synaptic connections have been well studied in a number of different systems, and they are known to be highly specific (cat: Eccles et al., 1957; Burke and Rudomín, 1977; chick: Fide et al., 1982; Lee et al., 1988; frog: Cruce, 1974; Tamarova, 1977; Frank and Westerfield, 1982a; Lichtman and Frank, 1984). Briefly, the connections are usually strongest between pairs of sensory and motor neurons projecting to the same muscle (homonymous connections), somewhat less strong between pairs projecting to different but functionally related muscles (synergistic connections), and relatively weak or nonexistent between pairs projecting to functionally unrelated or antagonistic muscles.

In the brachial spinal cord of the bullfrog, individual muscle afferents from the triceps brachii muscles arborize throughout the entire longitudinal extent of the brachial motor column (Lichtman et al., 1984), which is about 2 segments long, yet the majority of brachial motoneurons receive little direct input from these afferents (Frank and Westerfield, 1982a). Moreover, within the region containing triceps motoneurons, where the arborizations of triceps afferents are most elaborate (Lichtman et al., 1984), only about a third of the motoneurons project to triceps muscles. Nevertheless, triceps afferents project to triceps motoneurons about 10 times more strongly than to other motoneurons, also within this region, that supply the subscapular and pectoralis muscles (Frank and Westerfield, 1982a; Lichtman and Frank, 1984). A schematic diagram illustrating these connections is shown in the upper portion of Figure 1. The formation of specific synapses on subpopulations of motoneurons immediately adjacent to one another would appear to require either that muscle afferents recognize some chemical determinant present on certain motoneuronal types or that correlated patterns of activity in these neurons lead to the formation or stabilization of appropriate connections.

The experiments reported here were designed to determinc to what extent correlated activity patterns in muscle sensory and motor neurons are necessary for the formation of specific synaptic connections between these cells. The strategy of these experiments is shown schematically in the lower portion of Fig- 
ure 1. Motor innervation of the forelimb in bullfrog tadpoles was disrupted by resection of the ventral root shortly before these synaptic connections began to form (Frank and Westerfield, 1983; Jackson and Frank, 1987). Nonspecific reinnervation of forelimb muscles by regenerating motoneurons produced a major disruption of normal patterns of limb movement. Nevertheless, triceps muscle afferents formed their strongest projections to a distinct subpopulation of brachial motoneurons. These data indicate that in the absence of normal patterns of motor innervation of a limb, sufficient cues still exist to permit the formation of highly specific sets of synaptic connections. They therefore argue indirectly for the existence of chemical determinants that can determine the pattern of these connections.

A preliminary account of this work has appeared (Frank, 1987).

\section{Materials and Methods}

Surgical procedures. Ventral roots of the 2nd spinal nerve (nomenclature according to Ecker, 1889) were resected in approximately 50 bullfrog tadpoles (Rana catesbeiana) ranging in age from stage XIV to XVII (Taylor and Kollros, 1946). The tadpoles were anesthetized in $0.1 \%$ tricaine methane sulfonate and spinal segments $1-4$ on the right side were exposed via a dorsal laminectomy. The complete ventral root, from spinal cord to dorsal root ganglion (about $0.5 \mathrm{~mm}$ ), was removed without injuring the dorsal root; the cartilage removed during the laminectomy was then replaced and overlying skin sutured, and the tadpole was allowed to recover.

Labeling of motoneurons projecting to triceps brachii muscles. Tadpoles were reared through metamorphosis and kept for an additional $1-4$ months to allow time for muscle afferents to form stable synaptic connections with motoneurons. After simple behavioral tests of the affected forelimb were made (see Results), motoneurons projecting to triceps muscles in both forelimbs were retrogradely labeled with HRP (Boehringer Mannheim Type II) under tricaine anesthesia. On the control (left) side, a pellet of recrystallized HRP was applied to the freshly cut ends of all triceps branches. On the experimental side, $1-2 \mu 1$ of $20 \% \mathrm{HRP}$ in $\mathrm{dH}_{2} \mathrm{O}$ was injected into the medial and external triceps muscle heads. The frogs were then kept for an additional week to allow for transport of HRP.

Electrophysiology. The procedures used in preparing frogs for intracellular recording experiments have been described previously (Frank and Westerfield, 1982a, b; Sah and Frank, 1984; Smith and Frank, 1987). Briefly, the frogs were chilled in ice water, then decapitated, skinned, and eviscerated. Further dissection was carried out in oxygenated physiological saline solution at $6-8^{\circ} \mathrm{C}$. The spinal cord was quickly exposed via a dorsal laminectomy and branches of the brachial nerve on the experimental side were dissected and cut distally. The spinal cord was bisected along the dorsal-ventral midline and the preparation transferred to a recording chamber where it was perfused with oxygenated saline. The dissection was frequently made $16-18 \mathrm{hr}$ before recordings were made, in which case the cord was kept perfused at $4^{\circ} \mathrm{C}$; this procedure did not cause any decrement in synaptic potential amplitudes. Intracellular recordings were made at $14^{\circ} \mathrm{C}$ with $70-120 \mathrm{M} \Omega$ glass micropipettes filled with $2 \mathrm{M} \mathrm{KMeSO}_{4}$.

In the latter half of these experiments (including 2 of the 5 normal frogs used to provide control data), a saline with bicarbonate and $\mathrm{CO}_{2}$ (irstead of HEPES) as a buffer system was used. This change was based on an observation by Davidoff and Sears (1975) that synaptic potentials evoked by dorsal root stimulation and recorded extracellularly in ventral roots were larger using a bicarbonate- $\mathrm{CO}_{2}$ buffer system. The composition of this saline (in mM) was $\mathrm{Na}^{+}, 129 ; \mathrm{K}^{+}, 2.0 ; \mathrm{Ca}^{2+}, 3.0 ; \mathrm{Mg}^{2+}$, $1.0 ; \mathrm{Cl}^{-}, 122 ; \mathrm{HCO}_{3}{ }^{-}, 17 ; d$-glucose, 17 , aerated with $95 \% \mathrm{O}_{2}-5 \% \mathrm{CO}_{2}$. Synaptic potentials recorded intracellularly in this solution are larger, and it has been used in all subsequent experiments. The specificity of triceps sensory afferents for triceps motoneurons is the same as with HEPES-buffered saline, however, so results of experiments in both salines have been combined.

Spinal neurons antidromically activated by stimulating branches of the brachial nerve were identified as motoneurons. Synaptic potentials elicited by $1-2 \mathrm{~Hz}$ stimulation of individual peripheral nerves were
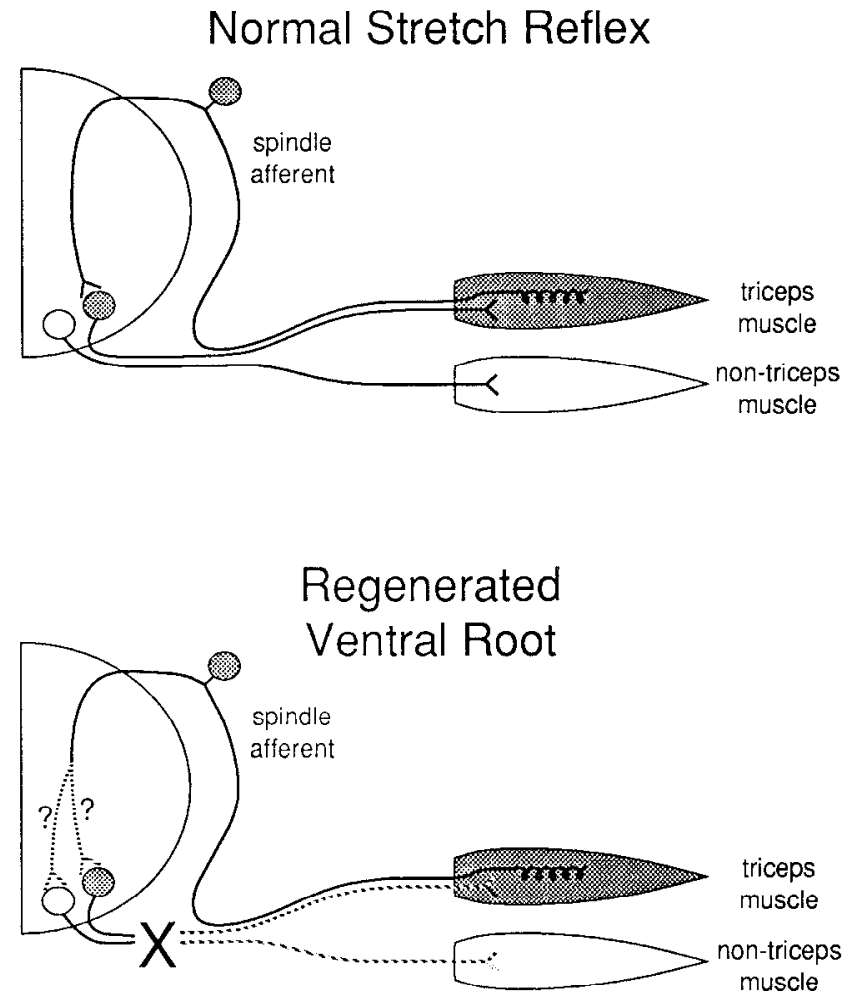

Figure 1. Schematic diagram of the normal monosynaptic stretch reflex (above) and of the experimental preparation (below). Normally, muscle spindle afferents supplying the triceps muscle project strongly to triceps motoneurons (shaded) but only weakly to nontriceps motoneurons (white) in the same region of the spinal cord. After resection of the ventral root in late-stage tadpoles ( $\mathrm{X}$ in lower figure), motoneurons reinnervate forelimb muscles randomly and produce abnormal patterns of limb movement. Synaptic connections between spindle afferents and motoneurons thus develop in the absence of normal patterns of stretchevoked activity.

averaged digitally and stored for further analysis (Smith and Frank, 1987) in neurons with resting potentials of at least $-40 \mathrm{mV}$. The internal and external branches of the triceps nerve were stimulated together because the afferents in these branches have virtually identical central connections (Lichtman and Frank, 1984). The latencies and amplitudes of these synaptic responses were measured and the latencies used to determine which potentials were evoked by monosynaptic connections between sensory and motor neurons ( $<6.0 \mathrm{msec}$ in these experiments). The specificity of these monosynaptic connections was determined by comparing the amplitude of the responses a particular muscle nerve evoked in different types of motoneurons. The methods used for measurement of monosynaptic inputs in this system have been discussed elsewhere (Frank and Westerfield, 1982a; Sah and Frank, 1984; Smith and Frank, 1987).

The selectivity of triceps muscle afferents for motoneurons supplying triceps and nontriceps (i.e., subscapularis and pectoralis) muscles was measured in each frog by calculating the average monosynaptic input each group of motoneurons received from medial and internal-external triceps afferents. A convenient measure of this selectivity is a specificity index (S.I.):

$$
\text { S.I. } \equiv(X-Y) /(X+Y) \text {, }
$$

where $X$ is the average triceps EPSP amplitude in triceps motoneurons and $Y$ is the average triceps EPSP amplitude in nontriceps motoneurons. This equation is a modification of one used earlier (Sah and Frank, 1984; Smith and Frank, 1987), with the advantage that negative values (when triceps afferents project more strongly to nontriceps motoneurons) are now defined.

Many neurons in the lateral motor column of frogs with regenerated ventral roots could not be antidromically activated by stimulation of peripheral nerve branches. Most of these probably were motoneurons 
Figure 2. Loss and nonspecific regeneration of axotomized brachial motoneurons. The 2 nd ventral root on the right side (Resected) was resected at stage $\mathrm{XVI}$ and allowed to regenerate. One month after metamorphosis, motoneurons projecting to triceps muscles on both sides were retrogradely labeled with HRP. These $50 \mu \mathrm{m}$ transverse sections (counterstained with neutral red) taken rostral to the triceps motor pool (note absence of HRP-labeled motoneurons in Control) include a motoneuron on the operated side (short arrow) whose axon inappropriately grew back to the triceps muscle. Also illustrated is the large loss of motoneurons after resection of the ventral root. The upper panels were photographed with a green filter to increase the visibility of non-HRPlabeled motoneurons. Scale bar, $400 \mu \mathrm{m}$ (upper panels), $100 \mu \mathrm{m}$ (lower panels).
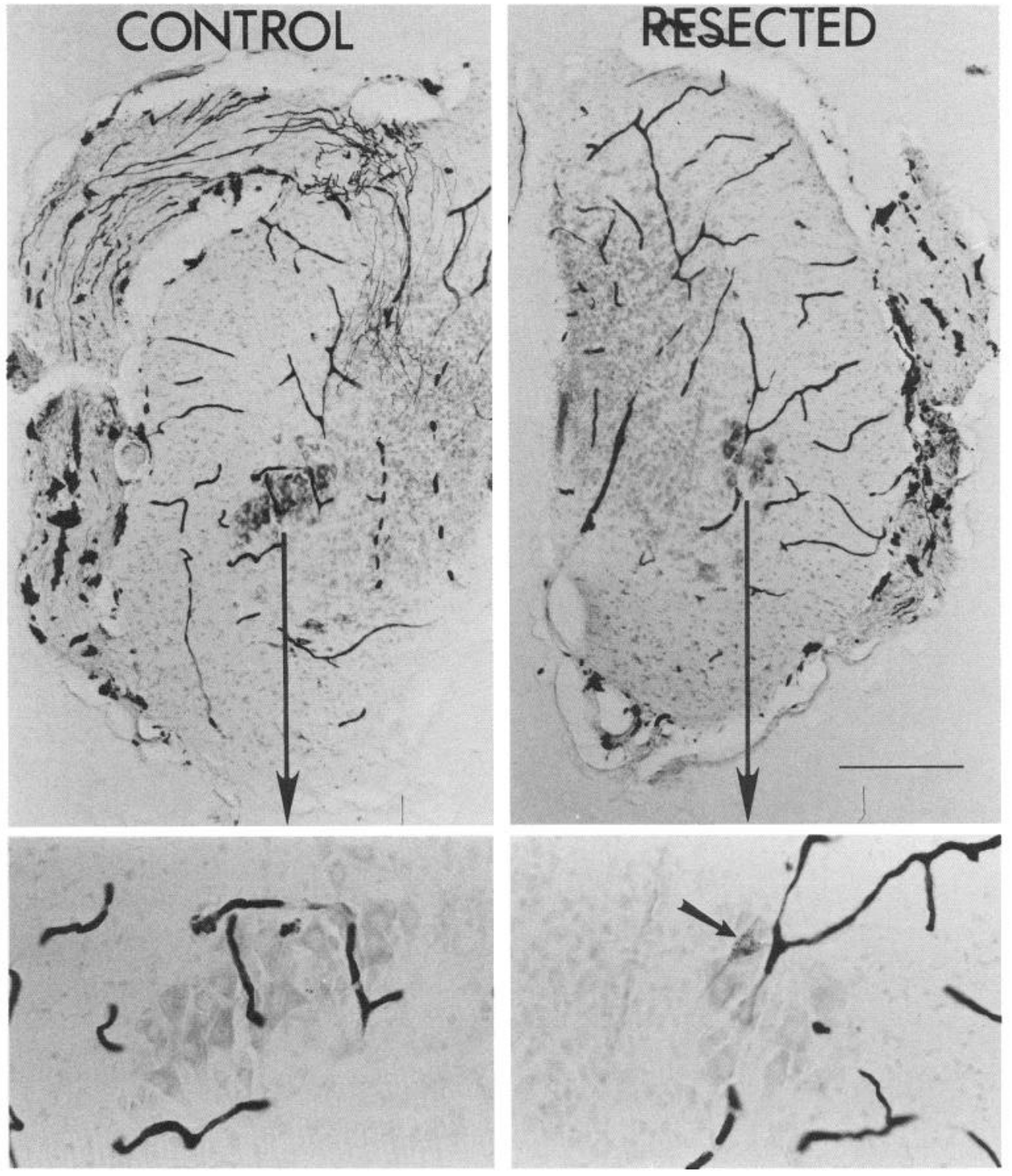

that failed to regenerate axons back into the forelimb (see Results). Analysis of synaptic potentials from these unidentified ventral horn neurons is included in Figures 6-8 and is treated separately in Figure 9.

Histology. Following the physiological recording sessions, control and experimental halves of the spinal cords were processed to identify the locations of motoneurons that had been retrogradely labeled with HRP (refer to Sah and Frank, 1984; Smith and Frank, 1987, for methods). Transverse serial sections, $50 \mu \mathrm{m}$, were used to determine the rostralcaudal position of every HRP-labeled cell. The normal position of the triceps motor pool was defined in each animal by the position of HRPlabeled neurons on the control side.

\section{Results}

Specificity of neuromuscular reinnervation

The experiments described here were designed to test whether functional motor innervation of the limb is required for the formation of specific synaptic connections between muscle spindle afferents and their target motoneurons. The strategy was to disrupt this motor innervation by resecting the 2 nd ventral root during development before spindle afferents begin to make synapses with motoneurons. Of course this resulted in a total loss of motor innervation at first, but because many axotomized motoneurons regenerated, they may have reestablished specific projections to forelimb muscles. It was therefore crucial to determine, for each experimental animal, the degree to which ventral root section resulted in chronic disruption of functional motor innervation throughout the period of study. Several independent tests were made to evaluate the degree and specificity of motor reinnervation at the end of the experimental period.

Complete data, including behavioral testing, retrograde labeling, and intracellular recording, were available for 15 frogs whose 2 nd ventral roots had been resected between stages XIV and XVII. Eleven of these frogs never used their reinnervated forelimbs for walking and never appeared to move their elbows actively. Within this group of 11 , only 2 could wiggle their toes in response to pinching of the affected or contralateral limb, a reflex that is easy to evoke in normal frogs. The forelimb muscles in 5 of these animals were severely atrophic, suggesting that motor innervation had been weak for at least a substantial period of time during development. These animals were, in general, more fully developed when their ventral roots were cut than those with more specific regeneration (see below). Of the 10 
frogs whose stage of development was noted, all but 2 had their ventral roots cut at stages XVI or XVII (average stage $=16.0$ ).

Further testing of the frogs in this group confirmed that regeneration of motoneurons was either nonspecific or weak, in that motoneurons died, failed to reinnervate forelimb muscles, or else reinnervated the incorrect muscles. The number of ventral horn neurons visible in transverse sections of spinal cords from these frogs was always reduced on the experimental side. An example of this loss of motoneurons is illustrated in Figure 2 , where the number of motoneurons was reduced to about half. In addition, many of the neurons that now projected to the triceps muscle were located in abnormal positions. Only $11 \%$ $(26 / 234)$ of motoneurons sampled in the normal triceps region of the spinal cord (as confirmed at the end of the experiment by the location of retrogradely labeled triceps motoneurons on the unoperated side) could be antidromically activated by stimulation of the triceps nerve in these animals. For comparison, in 4 normal frogs studied during the same period, $42 \%(43 / 102)$ of the motoneurons within this same region projected out the triceps nerve. In fact 93 of $292(32 \%)$ of the cells successfully penetrated in this region could not be antidromically activated from any of the peripheral nerves prepared for stimulation. This contrasts with only $13 \%$ of such cells in the 4 animals used as controls. The anatomical location of retrogradely filled triceps motoneurons told a similar story. Approximately half (149/280 $=53 \%$ ) of the motoneurons labeled by HRP applied to the triceps muscles lay outside the normal triceps pool (see example in Fig. 2), as defined by similar fills on the normal, contralateral side of each animal. The proportion of retrogradely labeled neurons lying outside the normal triceps pool varied from 24 to $100 \%$, with all but one greater than $40 \%$.

In contrast, the 4 other frogs with the same operation showed some signs of using their forelimbs. All held their affected limbs in the correct position at the completion of a leap, implying at lcast somc use of their shoulder. Two used the limb during walking, including elbow movements. None of the limbs was noticeably atrophic. As a group, these frogs were younger at the time of denervation (2 at stage XIV and 1 each at stages XV and XVI, average stage $=14.75$ ).

Physiological analysis of this second group of animals also indicated that motoneurons had reinnervated the forelimb more successfully. Only $11 \%$ of impaled neurons $(8 / 74)$ could not be antidromically activated by stimulation of a peripheral nerve. This is within the range encountered in normal frogs. Anatomically, many neurons retrogradely labeled by HRP from the triceps nerve or muscle lay outside the normal triceps motor pool $(37 / 97=38 \%$, individual animals varied from 28 to $71 \%)$, just as in the first group of frogs. Intracellular recordings, however, indicated that within the triceps motor pool a substantial fraction had grown back to the triceps muscles. Of the sampled neurons, 20 of $74=27 \%$ (vs. $42 \%$ in the 4 normal frogs) could be antidromically activated by stimulation of triceps nerves.

Functional specificity of synaptic connections between muscle afferents and motoneurons in the spinal cord

The poor motor reinnervation in frogs with regenerated motor axons did not prevent muscle afferents from innervating motoneurons. Synaptic potentials had normal latencies and the early, electrical component was prominent in many of the EPSPs, just as in normal frogs (see Frank and Westerfield, 1982a). Representative traces are shown in Figure 3. Not surprisingly, however, these connections were not functionally specific in the first group of frogs with nonspecific motor reinnervation. Triceps sensory afferents projected to triceps and nontriceps (i.e., subscapularis and pectoralis) motoneurons about equally; some of these projections were quite large, although most were relatively small. Amplitude histograms showing the combined results from all frogs are presented in Figure 4. As is evident in Figure $4 A$, most triceps motoneurons received very little triceps sensory input; the few that did get appreciable input might well be original triceps motoneurons that happened to reinnervate the triceps muscles. Similarly, although most motoneurons that now projected to the subscapularis or pectoralis muscles also got little triceps input, about $20 \%$ of these motoneurons had triceps EPSPs larger than $1 \mathrm{mV}$, something that is rarely seen in normal frogs (refer to Fig. 4C). These may well have been motoneurons that originally supplied the triceps muscles.

This absence of functional specificity is also apparent in individual animals; i.e., the histograms in Figure $4 A$ are not simply the result of combining large EPSPs from a few animals with small EPSPs from most others. An S.I. was calculated for cach frog that gives a measure of the preference triceps sensory afferents have for triceps versus nontriceps (subscapularis and pectoralis) motoneurons. These indices are plotted for experimental and normal frogs in Figure 5. Whereas the 4 normal frogs had S.I.'s of between 0.65 and 0.96 (within the range of all normal animals studied in this laboratory), the S.I.'s for the first group (nonspecific reinnervation) fell between -0.67 and +0.66 , with all but 2 less than 0.31 . Because a relatively small proportion of the sampled neurons projected to triceps, subscapularis or pectoralis muscles (see above), and most of these projections were of small amplitude (see Fig. $4 A$ ), the uncertainty of each S.I. value in this group is large. Seven of the 8 frogs had an S.I. that was not significantly different than $0(p>$ 0.1 , Mann-Whitney unpaired rank test). Three frogs in this group are not shown in Figure 5 because no motoneurons projecting to triceps and subscapularis or pectoralis muscles were encountered.

The pattern of triceps afferent connections in the second group of experimental frogs ("specific" reinnervation) was similar to that in normal frogs. The amplitude histograms in Figure $4 B$ show that many more motoneurons supplying the triceps muscles received significant triceps afferent input than in the first group. Triceps sensory projections to nontriceps motoneurons were also reduced. The results from individual frogs are shown in Figure 5. Three of the 4 animals had S.I.'s significantly ( $p<$ $0.01)$ greater than $0(0.01<p<0.05$ for the 4th animal), although the values fell in the lower part of the normal range.

\section{Do sensory afferents make specific connections in the absence} of coordinated patterns of activity?

The results presented so far do not distinguish between patterned activity or chemospecificity as plausible mechanisms ensuring the formation of appropriate sensory-motor connections. The 3 of 4 frogs from the second group with reasonably specific connections had at least some use of their affected limb, and it is likely that a number of original triceps motoneurons successfully reinnervated the triceps (rather than the subscapular or pectoralis) muscles. Hence the results are consistent with either mechanism. For the frogs with inappropriate triceps connections, activity patterns were likely to be highly abnormal because the animals did not move their elbows or use their forelimbs at all. But a hypothesis based on chemical recognition between triceps sensory afferents and original triceps motoneu- 

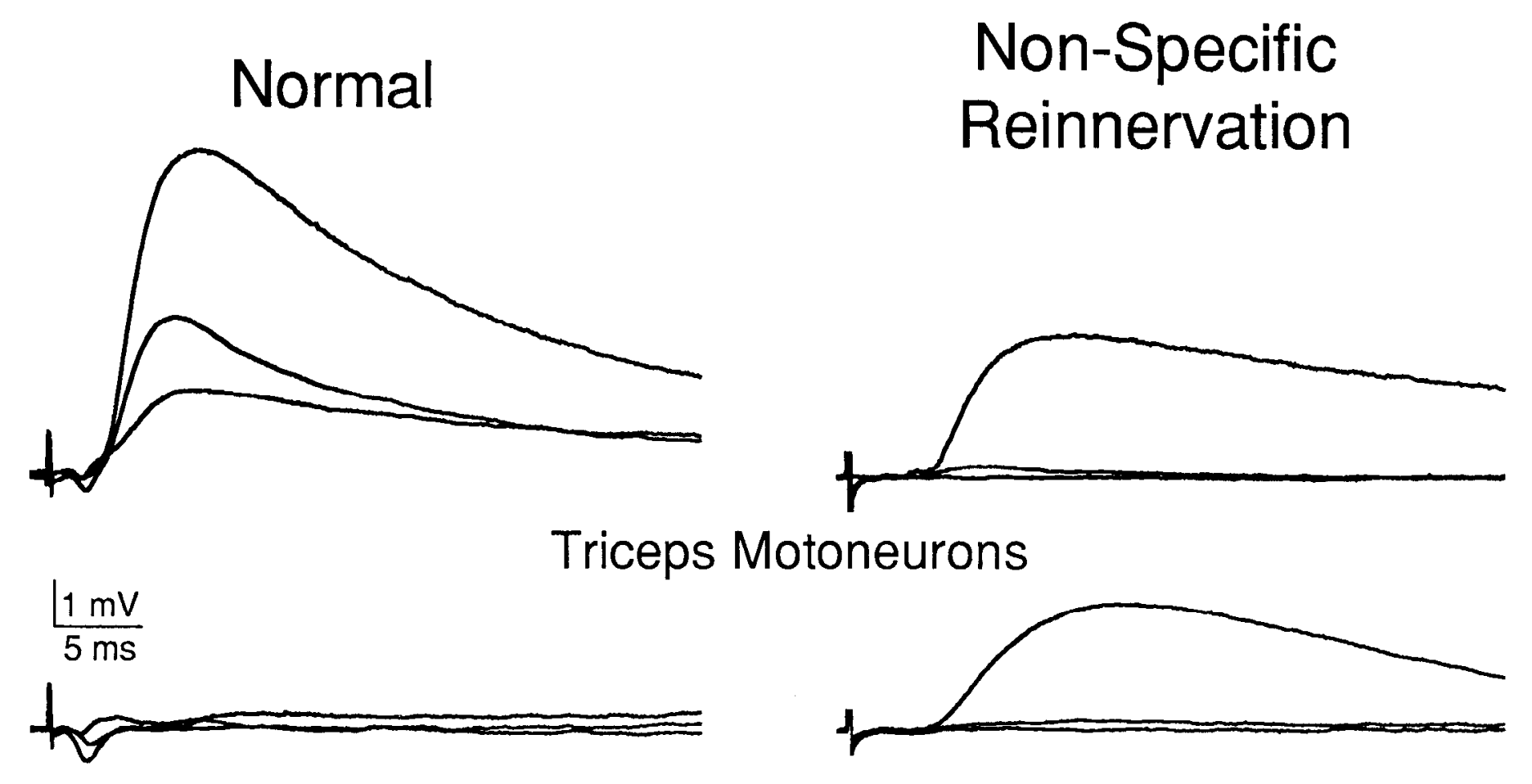

\section{Triceps Motoneurons}

\section{Subscapularis-Pectoralis Motoneurons}

Figure 3. Averaged triceps sensory EPSPs recorded from 12 brachial motoneurons, 6 in a normal frog (left) and 6 in a frog whose motoneurons regenerated nonspecifically after resection of the ventral root at stage XVI (right). Triceps sensory afferents project selectively to triceps versus nontriceps (subscapularis or pectoralis) motoneurons in the normal animal, but these projections are functionally inappropriate in the frog with nonspecific motor reinnervation. Note that motoneurons are identified by the muscle to which they project; for experimental frogs with nonspecific motor reinnervation this is usually different from their original target muscle.

rons would also predict "inappropriate" connections because most of these triceps motoneurons now supplied nontriceps muscles, including subscapularis and pectoralis. Since both activity and functionally appropriate chemospecific cues were removed, it is not surprising that functional specificity was abolished. To see if triceps sensory afferents are capable of distinguishing among various types of motoneurons in the absence of coordinated activity, one needs a method for recognizing these types in frogs with nonspecific motor reinnervation.

Fortunately, the normal pattern of connectivity between muscle spindle afferents and motoneurons provides a powerful way of differentiating among different motoneuronal types. Triceps sensory inputs to individual motoneurons are highly correlated; both medial and internal-external triceps muscle afferents innervate all types of triceps motoneurons more strongly than cither group of triceps afferents innervates other types of motoneurons. The input from one group of triceps afferents can therefore be used to classify motoneurons as "triceps-like" or "nontriceps-like" even when their actual identity cannot be checked by antidromic activation. One can then determine if the other group of triceps afferents selectively innervates "triceps-like" or "nontriceps-like" neurons.

The correlation between triceps inputs can be demonstrated by plotting the amount of input individual motoneurons receive from each of the 2 groups of afferents, as shown for a normal frog in the left part of Figure 6. Although there is some scatter in the points, any motoneuron that received more than $0.5 \mathrm{mV}$ of input from medial triceps afferents also received more than $0.5 \mathrm{mV}$ of input from the afferents in the internal and external triceps muscle nerves. All but 3 of these motoneurons projected to the triceps muscles. Nontriceps motoneurons received relatively little input from either group of triceps afferents.

A convenient way of comparing these correlations for a group of animals is to divide the total population of motoneurons into 2 groups: one with greater than and the other with less than 0.2 $\mathrm{mV}$ of input from the medial triceps afferents. As shown in the left panel of Figure 7, neurons in all 5 normal frogs with $\geq 0.2$ $\mathrm{mV}$ of medial triceps input had, on average, 10 times more input from the combined internal and external triceps afferents than those neurons with $<0.2 \mathrm{mV}$ of medial triceps input. All 39 triceps motoneurons fell into the right-hand column, while 19 of the 38 subscapular or pectoral motoneurons were in the left-hand one. As described previously (Frank and Westerfield, 1982a; Sah and Frank, 1984), some motoneurons projecting out the ulnar and radial nerves also have significant triceps input. The presence of these nontriceps motoneurons in the right-hand group does not diminish, however, the striking difference in the amount of input these 2 groups receive from internal-external triceps afferents.

This correlation of medial versus internal-external triceps afferent input provides a way of assessing the pattern of sensorymotor connections even in cases when, as in frogs with regenerated motor axons, the original identity of the motoneurons is unknown. The right panel of Figure 6 shows this correlation for the 30 motoneurons studied in one frog in which motor reinnervation was nonspecific (S.I. $=-0.39$ ). Functionally, the synaptic input from triceps sensory afferents was nonspecific; motoneurons that had regenerated to supply triceps muscles did 

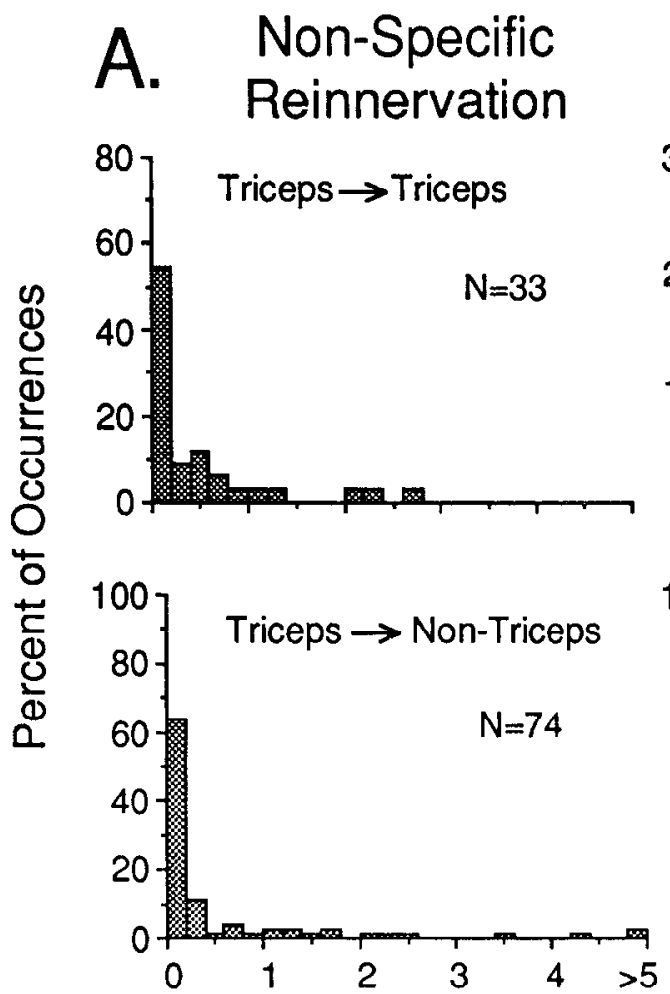
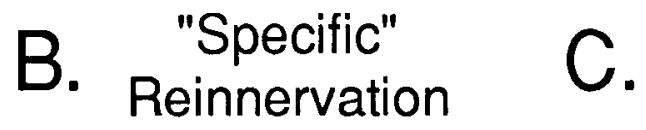

Normal
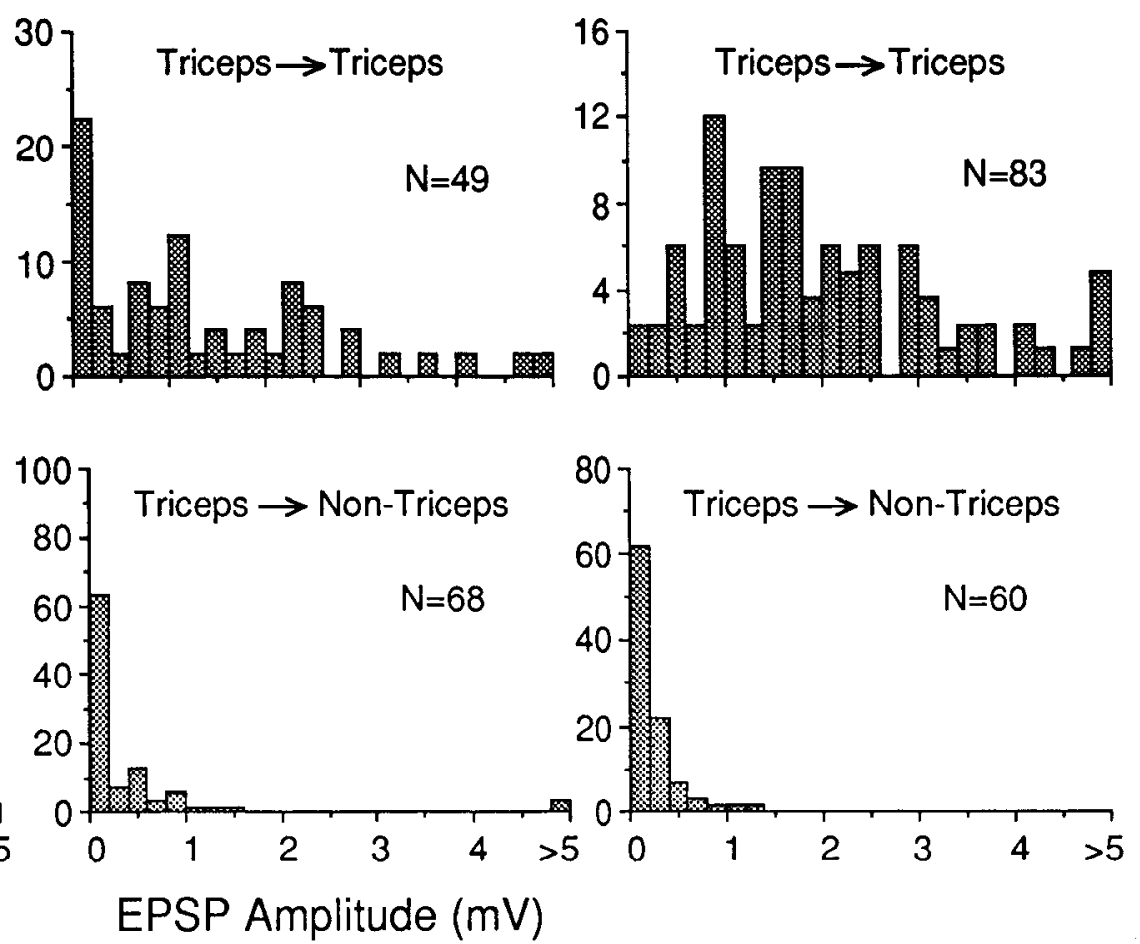

Figure 4. Amplitude histograms of monosynaptic EPSPs produced by triceps muscle sensory afferents in triceps and nontriceps (subscapularis and pectoralis) motoneurons in 3 groups of frogs. $A$, Results from the 11 frogs with nonspecific motor reinnervation. Most motoneurons (triceps as well as nontriceps) receive little triceps sensory input, although the input to a few motoneurons in both groups is quite large. $B$, Results from the 4 frogs with moderately specific motor reinnervation. Triceps sensory afferents show a clear preference for triceps versus nontriceps motoneurons, although over $20 \%$ of the triceps motoneurons receive $<0.2 \mathrm{mV}$ of triceps sensory input. $C$, Results from 4 normal frogs, showing the normal high level of specificity of triceps sensory projections. Few triceps motoneurons $(<3 \%)$ receive $<0.2 \mathrm{mV}$ of triceps sensory input and only $3 \%$ of nontriceps motoneurons had $>1.0 \mathrm{mV}$ of triceps input. The medial and combined internal-external triceps nerves (see Materials and Methods) were stimulated separately, and the upper histograms show both homonymous and synergistic triceps projections.

not receive particularly strong triceps sensory input. Whenever a motoneuron, of whatever type, did get strong input from medial triceps afferents, however, it also received significant input from afferents supplying the internal and external triceps heads. This strong correlation of medial and internal-external triceps inputs in an animal that could not move its forelimb suggests that the 2 groups of afferents were recognizing some feature of individual motoneurons that did not depend on patterned activity. The likely alternative is that chemical cues on the motoneurons were used instead.

For the computation of this correlation for all frogs with regenerated motor axons, it was important to exclude any animals which might have had specific motor reinnervation and hence some degree of coordinated motor activity (even if it was not visible after metamorphosis). This exclusion would rule out the possibility that coordinated activity could have contributed to the correlation. All frogs in the "specific" reinnervation group were therefore excluded. Within the nonspecific reinnervation group, the 2 frogs with the highest S.I.'s (0.66 and 0.54, refer to Fig. 5) were excluded on the basis that these indices might be evidence that some triceps motor reinnervation had, in fact, been specific. The only other frog with a positive S.I. in this group (S.I. $=0.31$, but not significantly different from 0 , refer to Fig. 5) was included because the triceps sensory input to motoneurons projecting to both triceps and subscapularis/pec-

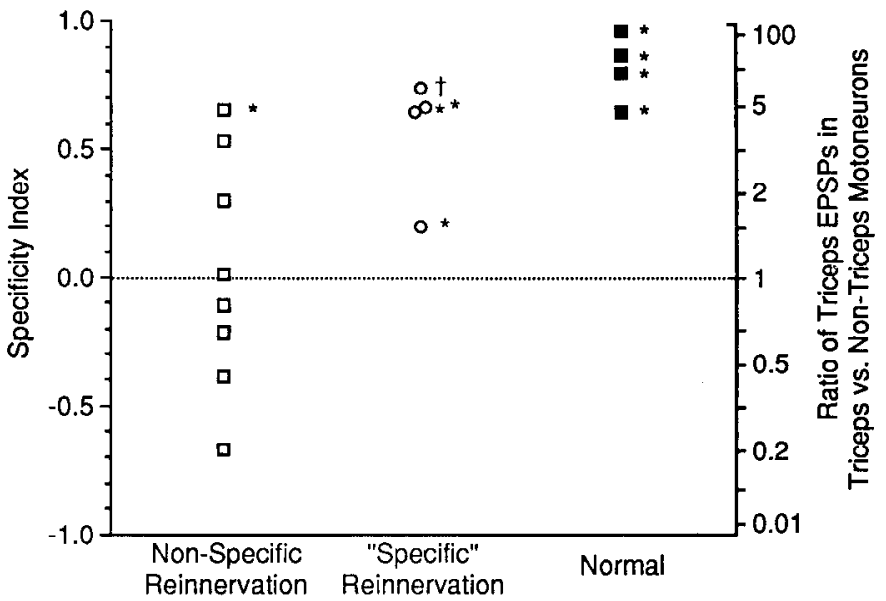

Figure 5. Functional specificity of monosynaptic projections of triceps sensory afferents to triceps versus nontriceps (subscapularis and pectoralis) motoneurons in the 3 groups of frogs. Each point represents the results from a single frog. The preference for triceps versus nontriceps motoneurons is expressed as a specificity index (S.I.; see Materials and Methods). The corresponding ratios of synaptic potential amplitudes in the 2 types of motoneurons, which give a more intuitive measure of synaptic preference, are shown on the axis to the right. Points that are significantly different from 0 (i.e., no preference for either group using the Mann-Whitney unpaired rank test) are indicated as follows: ${ }^{*} p<$ $0.01 ; \dagger 0.01<p<0.05$; no symbol, $p>0.1$ ). 
Figure 6. Correlation of monosynaptic potential amplitudes evoked by stimulation of medial versus internalexternal triceps muscle nerves (M. Triceps vs. I.E. Triceps) in individual motoneurons in a normal frog $(l e f t)$ and a frog with nonspecific motor reinnervation of its forelimb (right). Filled symbols represent triceps motoneurons, open symbols represent all others, including unidentified ventral horn neurons (see Materials and Methods). Normally, motoneurons with the largest triceps sensory input are all triceps motoneurons. For the experimental frog, however, motoneurons with large triceps sensory input usually do not project to triceps muscles. Nevertheless, the correlation between the 2 types of triceps sensory input to individual motoneurons is strong for both frogs $\left(R^{2}=0.64\right.$ for normal frog, 0.88 for experimental frog).

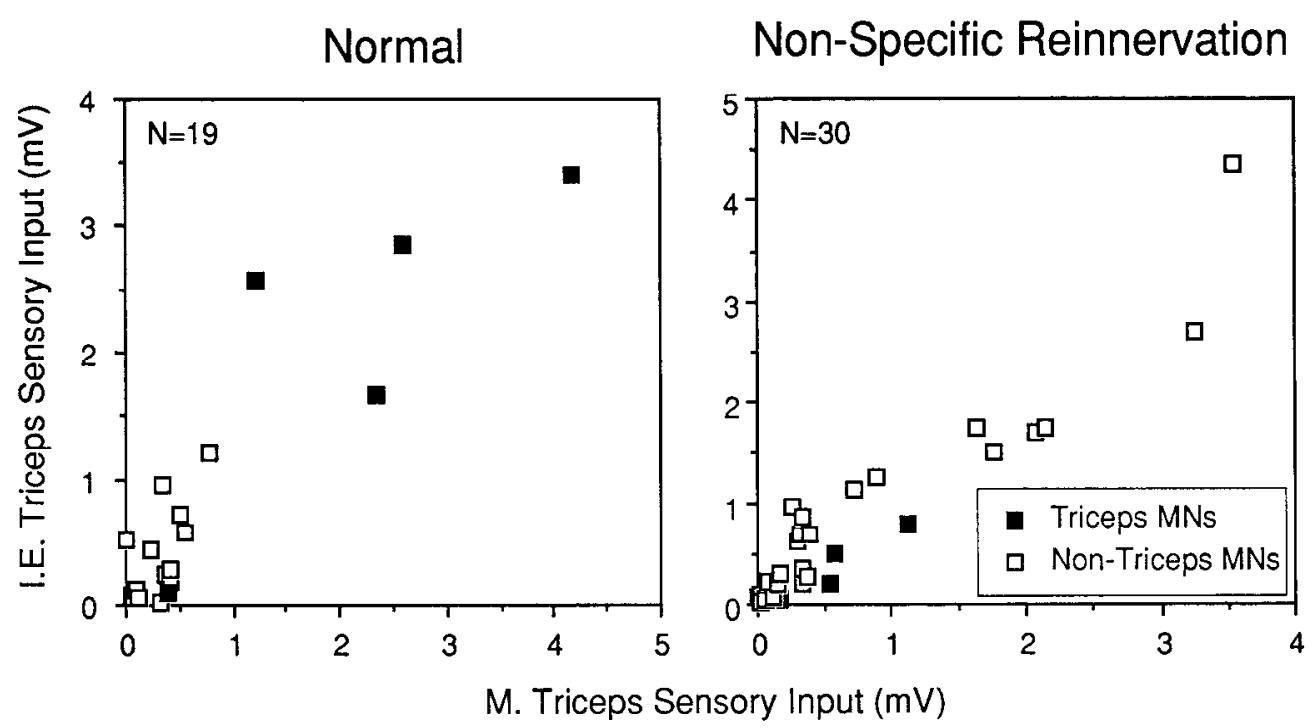

toralis muscles was small $(0.1-0.15 \mathrm{mV})$, yet these same afferents projected strongly to other motoneurons (13 of the 19 other motoneurons had $>0.5 \mathrm{mV}$ of input from medial triceps afferents). Finally, the results from 3 animals with nonspecific reinnervation that are not shown in Figure 5 because no triceps and/ or pectoralis/subscapularis motoneurons were encountered during the recording session are also included in this group.

The results from all these frogs (which had virtually no use of their forelimbs, nonspecific motor reinnervation, and inappropriate sensory-motor connections) are shown in Figure 7, right. Just as for the normal animals, motoneurons with $\geq 0.2$ $\mathrm{mV}$ of medial triceps afferent input had much larger inputs from the internal-external triceps afferents than those motoneurons with $<0.2 \mathrm{mV}$ medial triceps input. The 2 types of triceps inputs are correlated almost as well as in normal animals. In contrast to the results from normal frogs, 6 of the 15 motoneurons that now supplied the triceps muscle received very little $(<0.2 \mathrm{mV})$ medial triceps input. The implication is that both sets of triceps afferents selectively innervated the same subpopulation of brachial motoneurons regardless of the new peripheral target of those neurons. Moreover, the size of the subpopulation of motoneurons with $\geq 0.2 \mathrm{mV}$ medial triceps input was similar to that observed in the control group $(113 / 187=60$ vs $81 / 118=$ $67 \%$ ). This subpopulation may well be the same one innervated by triceps afferents in normal frogs.

\section{Correlation with synaptic input from other muscle afferents}

A straightforward interpretation of these results is that the 2 types of triceps afferents are similar to each other in the extent to which they find each motoneuron an attractive target. Either both types innervate a motoneuron or neither does. Inputs from nontriceps muscle afferents, which have different patterns of connectivity than triceps afferents in normal animals, should not be correlated with triceps inputs. An alternative explanation of the results in Figure 7, however, is that the correlation might simply reflect a difference among motoneurons in their attrac-

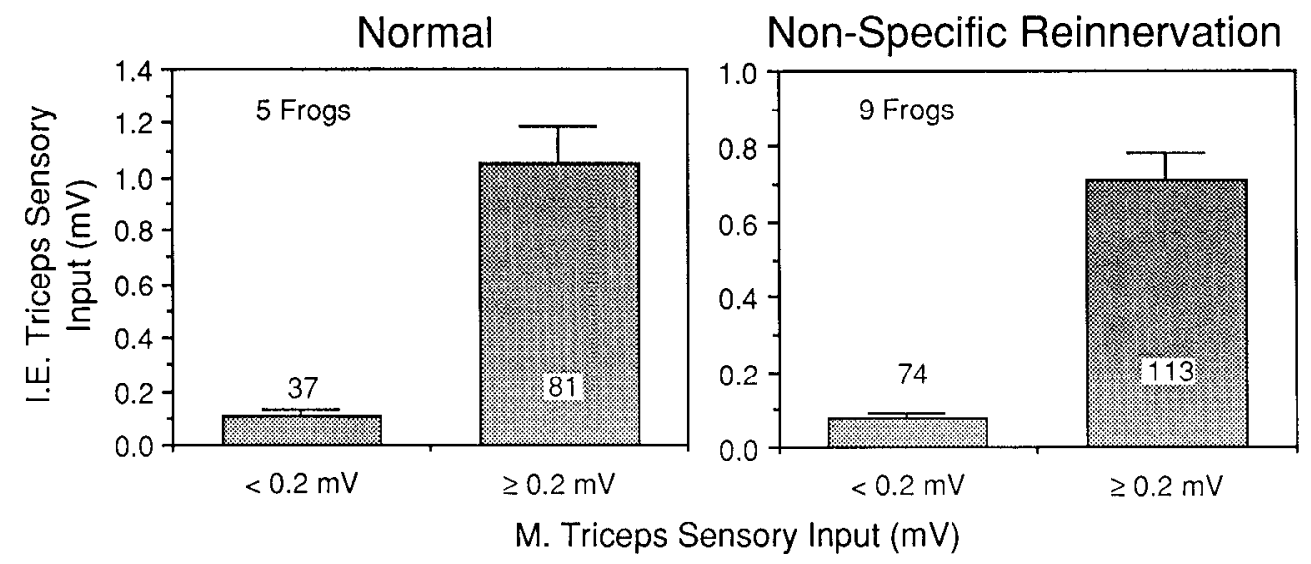

Figure 7. Correlation of monosynaptic inputs from medial and internal-external triceps sensory afferents to all motoneurons (including unidentified ventral horn neurons) in 5 normal frogs and in the 9 frogs with nonspecific motor reinnervation selected for analysis (see text for selection criteria). For each panel, all motoneurons with $<0.2 \mathrm{mV}$ of synaptic input from medial triceps afferents are grouped in one column, those with at least 0.2 $\mathrm{mV}$ of input are grouped in the other. Motoneurons that had significant $(\geq 0.2 \mathrm{mV})$ inputs from medial triceps afferents had a much larger input from internal-external triceps afferents than those that did not. The 2 groups of afferents thus selected the same subpopulation of motoneurons, even in frogs with nonspecific motor reinnervation. The number associated with each column indicates the number of motoneurons. Error bars show 1 SE of the mean. 


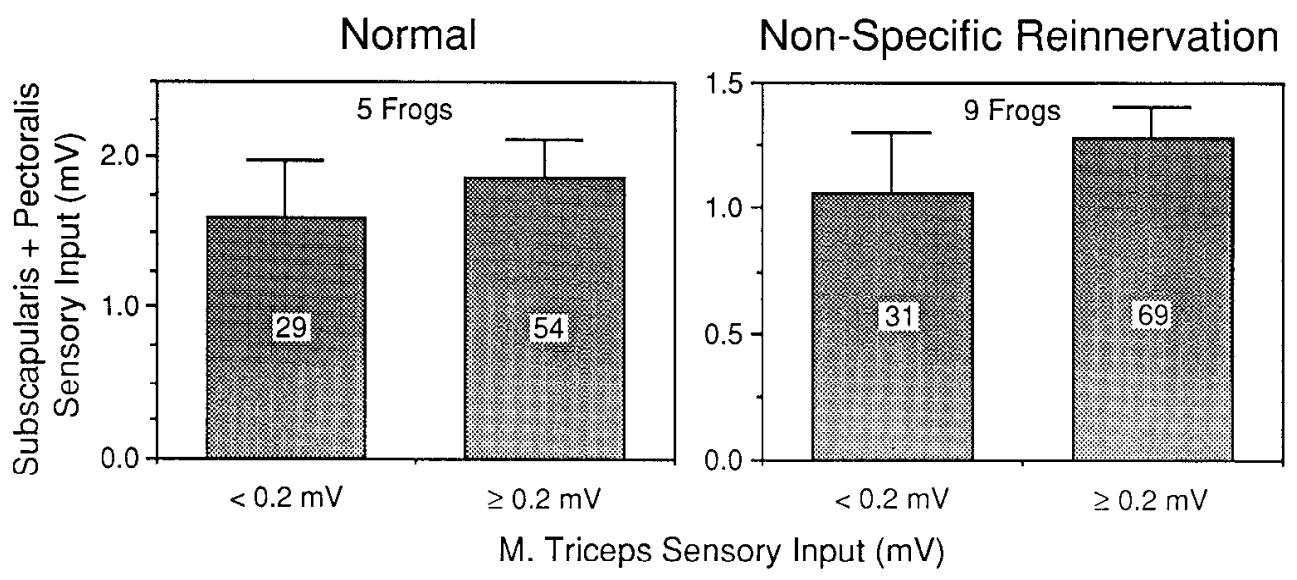

Figure 8. Absence of correlation of monosynaptic inputs from medial triceps and nontriceps (subscapularis + pectoralis) sensory afferents in the same groups of frogs as in Figure 7. The nontriceps input was measured by stimulating the subscapular and pectoral muscle nerves simultaneously. Motoneurons with little input from medial triceps afferents were just as likely to receive significant input from nontriceps afferents as those with large triceps input. The selective pattern of innervation shown in Figure 7 results not simply because some motoneurons are innervated by all muscle afferents while others are not innervated at all. The total number of motoneurons in each column is different than in Figure 7 because subscapular and pectoral inputs were not measured in every motoneuron.

tiveness for any muscle afferent. In that case, nontriceps inputs should be correlated with triceps inputs.

These alternatives were explored by measuring the synaptic input motoneurons received from other muscle afferents. Figure 8 shows the results of a comparison between medial triceps and combined subscapular/pectoralis inputs for both normal and experimental frogs, presented as in Figure 7. In this case, motoneurons with little input from medial triceps afferents received just as much input from the nontriceps muscle afferents as those motoneurons with $\geq 0.2 \mathrm{mV}$ of medial triceps input. Similar results were obtained using input from muscle afferents supplying the suprascapular, deltoid, and sternoradialis muscles. The mean resting potentials of motoneurons in the 2 groups were also not different ( $58 \pm 1.0 \mathrm{mV}$ in both groups). Therefore, the correlation between the 2 types of triceps sensory inputs does not simply reflect a general attractiveness of certain motoneurons for muscle sensory input, but rather implies that both types of triceps afferents recognize the same distinct subpopulation of brachial motoneurons.

\section{Projections to antidromically identified motoneurons versus unidentified ventral horn neurons}

A common feature of frogs with nonspecific motor reinnervation was that many (approximately one-third) of the neurons could not be antidromically activated by stimulation of any of the dissected peripheral nerves, whereas only about $10 \%$ of neurons sampled at the same spinal location in normal frogs cannot be so activated. Most of these unidentified neurons are likely to be motoneurons for the following reasons: (1) They were located in the same region of the spinal cord where identified motoneurons were found. Retrograde fills of the brachial nerve with HRP in normal frogs show that virtually every large neuron in this region is a motoneuron (unpublished observations; see, for example, Frank and Westerfield, 1982a). (2) Nonspecific regeneration would result in some motoneurons projecting into unusual peripheral nerves. Since not all brachial nerves were prepared for stimulation, these motoneurons could not be activated antidromically. (3) The peripheral axons of many regenerated motoneurons had abnormally high thresholds (presumably because their axons were small). Axons with thresholds $>3.5 \mathrm{~V}$ (approximately 3-4 times higher than normal) would not have been stimulated in most of the experiments. Recordings from unidentified ventral horn neurons have therefore been included in the data shown in Figures 6-8. Despite the likelihood that these cells really were motoneurons, it was important to test if their inclusion was critical to the observed correlation of different triceps inputs to motoneurons.

The data were divided into 2 groups, recordings from unidentified ventral horn neurons and from antidromically identified motoneurons, and are replotted in Figure 9. Although the standard crrors of cach mcan are necessarily larger, the correlation within each group is similar to that for the entire population. Correlations between medial triceps input and input from other, nontriceps muscle afferents, such as the one shown in Figure 8, were also similar when the data were divided in this way. Triceps afferents therefore innervate a specific subpopulation of identified (as well as unidentified) motoneurons.

\section{Discussion}

The conclusion from these experimental results that specific synaptic connections between muscle sensory and motor neurons can form in the absence of coordinated patterns of neural activity depends critically on the degree to which these patterns were successfully disrupted. Transection of motor axons in the brachial ventral root resulted in complete paralysis of the forelimb so that during the period before motor reinnervation had occurred, therc was no contraction-evoked activity of muscle afferents. Even activity in these afferents that might have been evoked by passive limb movements would not have been coordinated with activity in motoneurons. After motor axons had reinnervated forelimb muscles, there were still no coordinated movements of the limb since in all 11 animals accepted for testing, the reinnervation was nonspecific. In fact, these animals could not visibly move their elbows at all. This absence of virtually all active movement of the forelimb would also result in the absence of evoked activity in muscle afferents throughout the entire postoperative period. It is reasonable to conclude that temporal correlations of sensory and motor activity that might be present during normal development were severely disrupted by the experimental procedure. 
Figure 9. Correlation of medial and internal-external triceps sensory input to antidromically identified motoneurons (left panel) and unidentified ventral horn neurons (right panel) for the 9 frogs with nonspecific motor reinnervation used in Figures 7 and 8 . The 2 types of triceps sensory input are strongly correlated with each other in both groups of neurons.

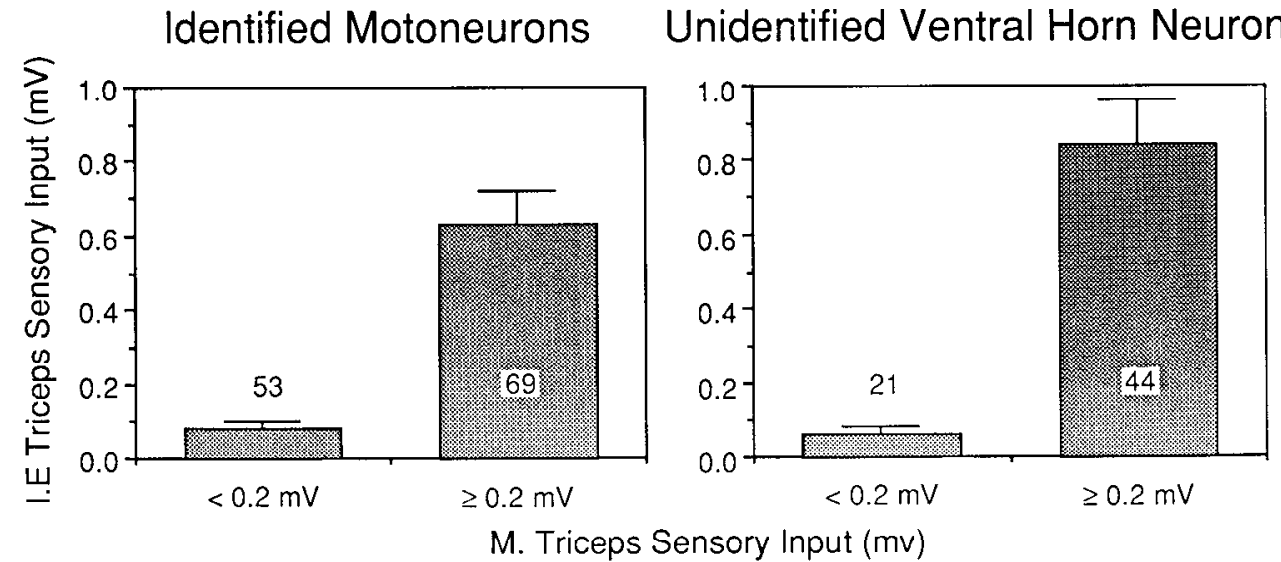

Despite the absence of normal patterns of muscle sensory activity in these frogs, afferent fibers supplying the triceps brachii muscles selectively innervated a restricted subpopulation of brachial motoneurons. Those motoneurons that received a significant $(\geq 0.2 \mathrm{mV})$ input from medial triceps afferents also received, on average, a much bigger input from internal-external triceps afferents than motoneurons that had little input from medial triceps afferents, just as in normal frogs. Inputs from other groups of muscle afferents were not correlated with medial triceps inputs, suggesting it is some special property common to all triceps afferents that caused them to innervate a common subpopulation of motoneurons. That common property is unlikely to be temporally correlated activity patterns in these animals. The most likely alternative would appear to be that triceps afferents express a chemical determinant on their growing axons that allows them to recognize and innervate selectively the appropriate brachial motoneurons.

These experiments provide the strongest evidence to date that the synaptic connections mediating the stretch reflex can be specified independently of patterned stretch-evoked activity in the afferent fibers. Earlier results, however, already suggested that the development of spindle afferent-to-motoneuron synapses was quite different than the development of ocular dominance columns in the visual system where activity is known to bc important. One important difference is the degree of specificity already present shortly after synaptic connections begin to form. In the visual cortex of cats, ocular dominance columns develop largely postnatally, after afferent fibers from the lateral geniculate have arborized and made functional connections in the cortex (LeVay et al., 1978; Shatz and Stryker, 1978). But in the stretch reflex system in frogs, synaptic specificity is apparent from the outsel. Triceps sensory fibers selectively innervate triceps motoneurons more strongly than subscapular or pectoralis motoneurons from the earliest stages that these connections can be detected, either electrophysiologically (Frank and Westerfield, 1983) or anatomically (Jackson and Frank, 1987). If activity in muscle spindle afferents was responsible for this specificity, it would need to be effective from the time the first connections are made.

In another series of experiments, the normal pattern of sensory input from triceps muscle spindles was disrupted during development, either by cutting the distal tendon of the medial triceps muscle (and thereby unloading the muscle spindles) or by transplanting this tendon onto the opposite surface of the radio-ulnar bone, thereby creating an elbow flexor instead of the normal elbow extensor (Frank and Jackson, 1986). For both types of manipulations, the result was clear cut; the pattern of connections between affected spindle afferents and motoneurons was normal. These observations are consistent with the idea that patterned neuronal activity of spindle afferents does not play a critical role in the development of specific sensory-motor connections. A potential problem with these experiments, however, is that it was not possible to verify directly that spindle afferents had been silenced by the tenotomy during the period that synapses were forming centrally. Activity was only checked at the end, when the animal was dissected and prepared for electrophysiological recording. And in the crossed tendon experiments, the surgical manipulation was only technically feasible a few stages after sensory-motor synapses had begun to form. Perhaps the "critical period" for an influence of patterned electrical activity had already occurred. The present experiments were therefore undertaken to provide more direct evidence on this issue.

It is important to point out explicitly that these results do not provide evidence against neural activity playing any role in the development of these connections. Only one measure of synaptic specificity was tested: whether 2 separate classes of triceps sensory afferents innervated a common pool of motoneurons. Because the original identity of the motoneurons was not known, it was not possible to determine if these afferents innervated their own, homonymous motoneurons more strongly than synergistic ones, or if connections with subscapular and pectoral motoneurons were specifically avoided, as in normal frogs. One can only conclude that at least some important aspects of synaptic specificity in this system can be determined in the absence of normal correlated patterns of activity.

Moreover, although activity patterns were certainly disrupted, it is not known whether these manipulations caused a cessation of spontaneous activity in the sensory afferents. Complete blockade of activity might lead to changes in connectivity that would not otherwise be seen. For example, the changes in $\mathrm{Ca}^{2+}$ levels in growth cones caused by trains of impulses are associated with dramatic changes in axonal growth rates (Mattson and Kater, 1987), and these changes might influence the synaptic connections these growth cones make (Kater et al., 1988). In fact, blockade of neural activity in several developing systems can lead to increases in the size of terminal arborizations of afferent fibers (Reh and Constantine-Paton, 1985; Sretavan et al., 1988; but see Hartlieb and Stuermer, 1989, for an absence of this effect for regenerating retinal ganglion cell axons in fish). 
Recent experiments by Nelson and his collaborators (1989) demonstrate that electrical stimulation of sensory neurons innervating spinal cord neurons in culture augments the strength of these synaptic connections. And in adult rats, silencing muscle sensory afferent fibers either by cutting the muscle nerve (Gallego et al., 1979) or by direct TTX blockade of peripheral axons (Manabe et al., 1989) results in a 30-60\% increase in the amplitude of the EPSPs these fibers produce in motoneurons. Preliminary experiments in chick embryos paralyzed for $10 \mathrm{~d}$ with curare also indicate an augmentation of EPSPs in motoneurons evoked by impulses in muscle afferents, although no abnormalities in synaptic connectivity have been noted (Mendelson and Frank, 1989, and unpublished observations).

Why might correlated patterns of neural activity be so important in determining the synaptic connectivity of some systems yet much less important in others? One possibility relates to the fact that in systems where activity is known to be crucial, such as in the visual pathway, the inputs that are affected are the dominant ones. In contrast, input from muscle spindles forms a relatively modest fraction of the total drive to spinal motoneurons (Rogers, 1972). Perhaps weaker inputs are not influenced by activity. This does not appear to be a compelling reason, however. Large inputs would certainly be necessary if they themselves were required to set up the postsynaptic activity that reinforced appropriate connections. But the postulated temporal correlations in the stretch reflex system would come from stretch-induced activity in the sensory fibers. Activity in appropriate pre- and postsynaptic partners could be correlated (or anticorrelated) even if the spindle afferents were completely ineffectual in driving the motoneurons themselves. It will be interesting to make a crucial test of this idea, however, by studying other developing systems in which a high degree of specificity is shown by relatively weak inputs.

A second idea is that chemoaffinity mechanisms are used in systems that are evolutionarily old, while activity-dependent mechanisms predominate in newer areas of the nervous system. As pointed out by Easter et al. (1985), many of the systems where activity-dependent mechanisms have been best demonstrated are in such newer areas, the visual and somatosensory cortex, for example, while the development of synaptic connections in lower vertebrates and invertebrates is often highly stereotyped and not obviously dependent on activity. But now there is convincing evidence that synaptic patterns in some invertebrate systems are shaped by competitive interactions during development (cricket: Murphey and Lemere, 1984; Murphey, 1986; leech: Kramer et al., 1985; Kramer and Stent, 1985), and some of these interactions are likely to involve neural activity (cricket: Matsumoto and Murphey, 1977; crayfish: Lnenicka and Atwood, 1985). In the visual system of lower vertebrates, a strong case can also be made for the importance of neural activity in determining the pattern of retinotectal projections (see below). Conversely, it will be interesting to see to what extent certain types of connections within "newer" areas are made in an activity-independent manner. But in any case, whether a particular system is evolutionarily old or new is unlikely to be a strong predictor of the importance of neural activity.

A third possibility is that activity-dependent mechanisms are largely restricted to systems where functionally appropriate synaptic connections cannot be specified in advance. In the visual system, for example, it is difficult to imagine how cortical neurons could be prespecified to be selective for a particular ori- entation of a visual stimulus, because different but overlapping subsets of geniculate afferents must project to different cortical cells. Once the initial connections have been made, however, synaptic strengths could be modified in a use-dependent manner to generate orientation specificity (see Frégnac and Imbert, 1984, for a comprehensive review). Another example comes from studies in fish and frogs where 2 eyes are forced to innervate a normally monocular tectum. Inputs from the 2 eyes sort out to innervate distinct, nonoverlapping subsets of tectal cells (Levine and Jacobson, 1975; Constantine-Paton and Law, 1978; Schmidt, 1978), producing artificial "ocular dominance" patches or stripes. The tectal neurons supplied by the extra eye are unlikely to come from a special, predetermined population, so ingrowing retinal ganglion cells could not "know" which tectal cells to innervate. Instead, competitive interactions between afferents from the 2 eyes (probably based on temporal correlations of activity in afferents from the same eye) appear to produce these monocular patches or stripes; abolition of retinal activity with TTX (Meyer, 1983; Boss and Schmidt, 1984; Reh and Constantine-Paton, 1985) or of synaptic transmission in the tectum with a glutamate receptor blocker (Cline et al., 1987) blocks their formation.

The synaptic connections between muscle spindle afferents and motoneurons are quite different. Both the sensory and the motor neurons already project to particular muscles and thus have distinct functional identities before the synaptic connections between them are established (chick: Lee et al., 1988; Davis et al., 1989; frog: Frank and Westerfield, 1983; Jackson and Frank, 1987). It is possible, then, that sufficient information is available for the appropriate synaptic connections to form from the outset, with little or no subsequent remodeling, as appears to be the case in the frog's spinal cord. In such systems, activitydependent synaptic refinements would be unnecessary and may not exist.

\section{References}

Boss VC, Schmidt JT (1984) Activity and the formation of ocular dominance patches in dually innervated tectum of goldfish. J Neurosci 4:2891-2905.

Burke R, Rudomín P (1977) Spinal neurons and synapses. In: Handbook of physiology: Sec. 1, Vol 1. The nervous system: the cellular biology of neurons (Kandel E, ed), pp 877-944. Bethesda, MD: American Physiology Society.

Cline H, Debski E, Constantine-Paton M (1987) N-methyl-D-aspartate receptor antagonist desegregates eye-specific stripes. Proc Natl Acad Sci USA 84:4342-4345.

Constantine-Paton M, Law MI (1978) Eye specific bands in the tecta of three-eyed frogs. Science 202:639-641.

Cruce WLR (1974) The anatomical localization of hindlimb motoneurons in the lumbar spinal cord of the frog, Rana catesbeiana. $\mathrm{J}$ Comp Neurol 153:59-76.

Davidoff R, Sears E (1975) Effects of synthetic buffers on reflexes in the isolated frog spinal cord. Am J Physiol 229:831-837.

Davis B, Frank E, Johnson F, Scott S (1989) Development of central projections of lumbosacral sensory neurons in the chick. J Comp Neurol 279:556-566.

Easter SS, Purves D, Rakic P, Spitzer NC (1985) The changing view of neural specificity. Science 230:507-511.

Eccles JC, Eccles RM, Lundberg A (1957) The convergence of monosynaptic excitatory afferents onto many different species of alpha motoneurones. J Physiol (Lond) 137:22-50.

Ecker A (1889) The anatomy of the frog. Oxford, UK: Clarendon Press.

Eide A-L, Jansen JKS, Ribchester RR (1982) The effect of lesions in the neural crest on the formation of synaptic connexions in the embryonic chick spinal cord. J Physiol (Lond) 324:453-478.

Frank E (1987) Specific synaptic connections between muscle sensory 
and motor neurons form in the absence of coordinated patterns of muscle activity. Soc Neurosci Abstr 13:1456.

Frank E, Jackson PC (1986) Normal electrical activity is not required for the formation of specific sensory-motor synapses. Brain Res 378 : 147-151.

Frank E, Westerfield M (1982a) Synaptic organization of sensory and motor neurones innervating triceps brachii muscles in the bullfrog. J Physiol (Lond) 324:479-494.

Frank E, Westerfield M (1982b) The formation of appropriate central and peripheral connexions by foreign sensory neurones of the bullfrog. J Physiol (Lond) 324:495-505.

Frank E, Westerfield M (1983) Development of sensory-motor synapses in the spinal cord of the frog. J Physiol (Lond) 343:593-610.

Frégnac Y, Imbert M (1984) Development of neuronal selectivity in primary visual cortex of cat. Physiol Rev 64:325-434.

Gallego R, Kuno M, Nunez R, Snider WD (1979) Disuse enhances synaptic efficacy in spinal motoneurons. J Physiol (Lond) 291:191205.

Hartlieb E, Stuermer C (1989) Pathfinding and target selection of goldfish retinal axons regenerating under TTX-induced impulse blockade. J Comp Neurol 284:148-168.

Jackson PC, Frank E (1987) Development of synaptic connections between muscle sensory and motor neurons: anatomical evidence that postsynaptic dendrites grow into a preformed sensory neuropil. $\mathbf{J}$ Comp Neurol 255:538-547.

Kater S, Mattson M, Cohan C, Connor J (1988) Calcium regulation of the neuronal growth cone. Trends Neurosci 11:315-321.

Kramer A, Stent G (1985) Developmental arborization of sensory neurons in the leech Haementeria ghilianii. II. Experimentally induced variations in the branching pattern. J Neurosci 5:768-775.

Kramer A, Goldman J, Stent G (1985) Developmental arborization of sensory neurons in the leech Haementeria ghilianii. I. Origin of natural variations in the branching pattern. J Neurosci 5:759-767.

Lee M, Koebbe M, O'Donovan M (1988) The development of sensorimotor synaptic connections in the lumbosacral cord of the chick embryo. J Neurosci 8:2530-2543.

LeVay S, Strykcr MP, Shatz CJ (1978) Ocular dominance columns and their development in layer IV of the cat's visual cortex: a quantitative study. J Comp Neurol 179:223-244.

Levine R, Jacobson M (1975) Discontinuous mapping of retina into tecta innervated by both eyes. Brain Res $98: 172-176$.

Lichtman JW, Frank E (1984) Physiological evidence for specificity of synaptic connections between individual sensory and motor neurons in the brachial spinal cord of the bullfrog. J Neurosci 4:17451753.

Lichtman JW, Jhaveri S, Frank E (1984) Anatomical basis of specific connections between sensory axons and motor neurons in the bullfrog's brachial spinal cord. J Neurosci 4:1754-1763.

Lnenicka G, Atwood H (1985) Age dependent long-term adaptation of crayfish phasic motor axon synapses to altered activity. J Neurosci $5: 459-467$.
Manabe T, Kaneko S, Kuno M (1989) Disuse-induced enhancement of Ia synaptic transmission in spinal motoneurons of the rat. J Neurosci 9:2455-2461.

Matsumoto S, Murphey R (1977) Sensory deprivation during development decreases the responsiveness of cricket giant interneurones. I Physiol (Lond) 268:533-548.

Mattson M, Kater S (1987) Calcium regulation of neurite extension and growth cone motility. J Neurosci 7:4034-4043.

Mendelson B, Frank E (1989) The formation of specific monosynaptic sensorimotor connections in chick embryos is not dependent on patterned neuronal activity or motoneuronal cell death. Soc Neurosci Abstr 15:126.

Meyer RL (1983) Tetrodotoxin inhibits the formation of refined retinotopography in goldfish. Dev Brain Res 6:293-298.

Murphey R (1986) Competition and the dynamics of axon arbor growth in the cricket. J Comp Neurol 251:100-110.

Murphey R, Lemere C (1984) Competition controls the growth of an identified axonal arborization. Science 224:1352-1355.

Nelson P, Yu C, Fields R, Neale E (1989) Synaptic connections in vitro: modulation of number and efficacy by electrical activity. Science 244:585-587.

Reh T, Constantine-Paton M (1985) Eye-specific segregation requires neural activity in three-eyed Rana pipiens. J Neurosci 5:1132-1 143.

Rogers D (1972) Ultrastructural identification of degenerating boutons of monosynaptic pathways to the lumbrosacral segments in the cat after spinal hemisection. Exp Brain Res 14:293-311.

Sah DWY, Frank E (1984) Regeneration of sensory-motor synapses in the spinal cord of the bullfrog. J Neurosci 4:2784-2791.

Schmidt J (1978) Retinal fibers alter tectal positional markers during the expansion of the half retinal projection in goldfish. J Comp Neurol 177:279-300.

Shatz CJ, Stryker MP (1978) Late segregation of geniculate afferents to the cat's visual cortex and the effects of monocular deprivation. $J$ Physiol (Lond) 281:267-283.

Smith CL, Frank E (1987) Peripheral specification of sensory neurons transplanted to novel locations along the neuraxis. J Neurosci 7:15371579.

Sretavan D, Shatz C, Stryker M (1988) Modification of retinal ganglion cell axon morphology by prenatal infusion of tetrodotoxin. Nature 336:468-471.

Tamarova ZA (1977) Excitatory postsynaptic potentials induced in the frog lumbar motoneurones by muscle and cutaneous nerve stimulation. Sechenov J Physiol (USSR) 63:806-813.

Taylor AC, Kollros JJ (1946) Stages in the normal development of Rana pipiens larvae. Anat Rec 94:7-23.

Westerfield M, Frank E (1982) Specificity of electrical coupling among neurons innervating forelimb muscles of the adult bullfrog. J Neurophysiol 48:904-913. 